\title{
Improving Education Precision and Poverty Alleviation based on Big Data
}

\author{
Chenghui Yang \\ College of Electrical Engineering \\ Northwest Minzu University \\ Gansu, China \\ yangchenghui36@163.com
}

\author{
Yifeng Zheng \\ College of Electrical Engineering \\ Northwest Minzu University \\ Gansu, China \\ 1544897186@qq.com
}

\begin{abstract}
With the increase of the state's investment in "poverty alleviation", it is of great significance to realize the poverty alleviation of impoverished college students, but at present, the criteria for judging whether students are poor are not clear so we cannot accurately and quickly determine the targets of accurate poverty reduction. From the perspective of big data modeling, this paper puts forward practical construction planning and improvement means to help to achieve the goal of accurate determination of impoverished students.
\end{abstract}

Keywords-Big data; Improving Education; Accurate poverty alleviation; Identification of poor students

\section{INTRODUCTION}

Poverty is a social phenomenon associated with the process of human development. Whether to deal with poverty is directly related to social harmony and stability. For a long time, the study of education poverty alleviation is based on the theory of poverty, a kind of countermeasures. From the perspective of economics, education, politics, anthropology to analyze the problem of poverty is somewhat one - sided, because the causes of poverty is diverse [1-2]. And through the means of big data can be analyzed from different angles to get a comprehensive and accurate results.

At present, the state attaches great importance to the problem of financial support for students with family economic difficulties in colleges and universities, and establishes a sound student financial support policy system to ensure that students with family economic difficulties have equal access to education as an important measure and way to promote educational equity [3]. And in colleges and universities set up a national scholarship, national incentive scholarships [4-5], national grants, national student loans, work-study grants, tuition fees relief and other forms of organic combination of college students with family difficulties to help students with family economic difficulties to complete their studies smoothly.

\section{METHODS}

Now the traditional way to identify the poor students first to fill in the family economic situation questionnaire, family financial difficulties of the identification table, but also to do relevant proof. After the school received the relevant materials, first in the class Democratic review, student representatives vote, and then series of audit, if no objections, then the list to the school funding center. But the traditional group voting method is too subjective, and in practice sometimes it tastes because of some reasons. For example, if a false proof is made, a conscientious person will get it, and a simple review can be passed by a conscientious person. More objective and convincing results can be obtained if more quantified items are added to the assessment process. The development of these complementary methods of evaluation is probably this:

(1) Fuzzy comprehensive evaluation method, not much said, the method is subjective in nature.

(2) Based on data-driven discriminant method

This kind of method benefits from the consummation of the university misinformation, through the school Wisdom Campus , Colleges and universities have accumulated many students ' behavior data in school, the behavior data is objective and real and easy to obtain, so more and more scholars have established the method of identifying poor students. This topic focuses on the "6 precise" general requirements of the provincial government of Gansu province, aiming at accurate poverty alleviation in the field of education, using large data and mobile internet technology to provide accurate support to needy students. With the research of data warehouse and data mining technology, we can provide accurate data support for poor students in order to achieve the goal of precision poverty alleviation.

TABLE I. STUDENTS ' BEHAVIOR DATA IN SCHOOL

\begin{tabular}{|c|c|l|c|}
\hline \multicolumn{3}{|c|}{ Students consumption of meals a day } \\
\hline $\begin{array}{c}\text { Three meals } \\
\text { a day }\end{array}$ & $\begin{array}{c}\text { Meal } \\
\text { time }\end{array}$ & $\begin{array}{l}\text { Dining } \\
\text { place }\end{array}$ & $\begin{array}{c}\text { Average meal } \\
\text { amount }\end{array}$ \\
\hline breakfast & $7: 15$ & $\begin{array}{l}\text { Muslims' } \\
\text { canteen; }\end{array}$ & 1.48 \\
\hline lunch & $11: 45$ & $\begin{array}{l}\text { Muslims' } \\
\text { canteen; }\end{array}$ & 7.40 \\
\hline dinner & $18: 10$ & $\begin{array}{l}\text { Muslims' } \\
\text { canteen; }\end{array}$ & \\
\hline
\end{tabular}




\section{BIG DATA ERA}

"Big Data" refers to the data involved, the volume of data is too large to pass through the human brain and even mainstream software tools. The large data is characterized by large amount of data, many kinds of data, strong real-time demand and great value of data. In all walks of life there are large data, but a large number of information and consultation is complex, we need to search, processing, analysis, induction, summary of its deep-seated rules of large data mining and processing. Large data is a large, dynamic, sustainable data, through the use of new systems, new tools [6], new models of mining, so as to gain insight and new value of things. In the past, we may be blinders and visible in the face of huge data, so we can not understand the true nature of things, and thus get the wrong inference in scientific work, and the advent of the big data age, all the truth will slowly unfold in front of us.

\section{RECOGNITION OF LARGE DATA IN THE IDENTIFICATION OF POOR STUDENTS}

The data of the campus card consumption can objectively and completely reflect the consumption information of a classmate in school, which can be analyzed by the consumption characteristics of the impoverished students. According to the data of poor students, the students are divided into four categories: poor students, first-level poor students, two-level impoverished students and non-poor students. Among them, according to one card consumption data can be divided into three observation points: dining times, average meal amount and dining amount fluctuation. The consumption of meals is the most reflective of a student's standard of living, poor students in the canteen must be more than the number of poor students, and in the amount of consumption is less than poor students. By normalized processing of data and Euclidean distance method to get a similarity data for each student the lower the L,L value, the higher the similarity between the student and the impoverished students, which provides a quantitative index for the assessment of students ' living condition. In addition, should also be based on the students in the canteen, supermarket consumption data statistics corresponding to each student canteen consumption of a single consumption amount distribution, supermarket consumption of a single consumption amount distribution, which is conducive to more accurate description of student consumption capacity and canteen consumption frequency, clustering data cleaning and some conversion (normalized/descending dimension) Very important, the effect on the result is very big; then, according to the distribution information, the students are grouped into subgroups with different consumption level and canteen consumption frequency, clustering algorithm selection and clustering effect evaluation should be done; Finally, the index can be set up, so long as the students can choose lower consumption level, Finally, the relative poor subgroups were selected, the students are considered to be poor. In order to judge the poverty index more accurately, it can be based on the campus large Data Environment [7-8], first, according to the historical data of the impoverished students who have passed the survey of poverty status, take One-third as the analysis sample set T1 and two-thirds as the test sample set T2; The second is to collect all the students in a certain period of time the campus card consumption records according to the training sample set to the poverty standard line [9]; The third is to calculate the distance between all the students and the poverty standard line in order to get the poverty index after normalized treatment shown in figure 1 .

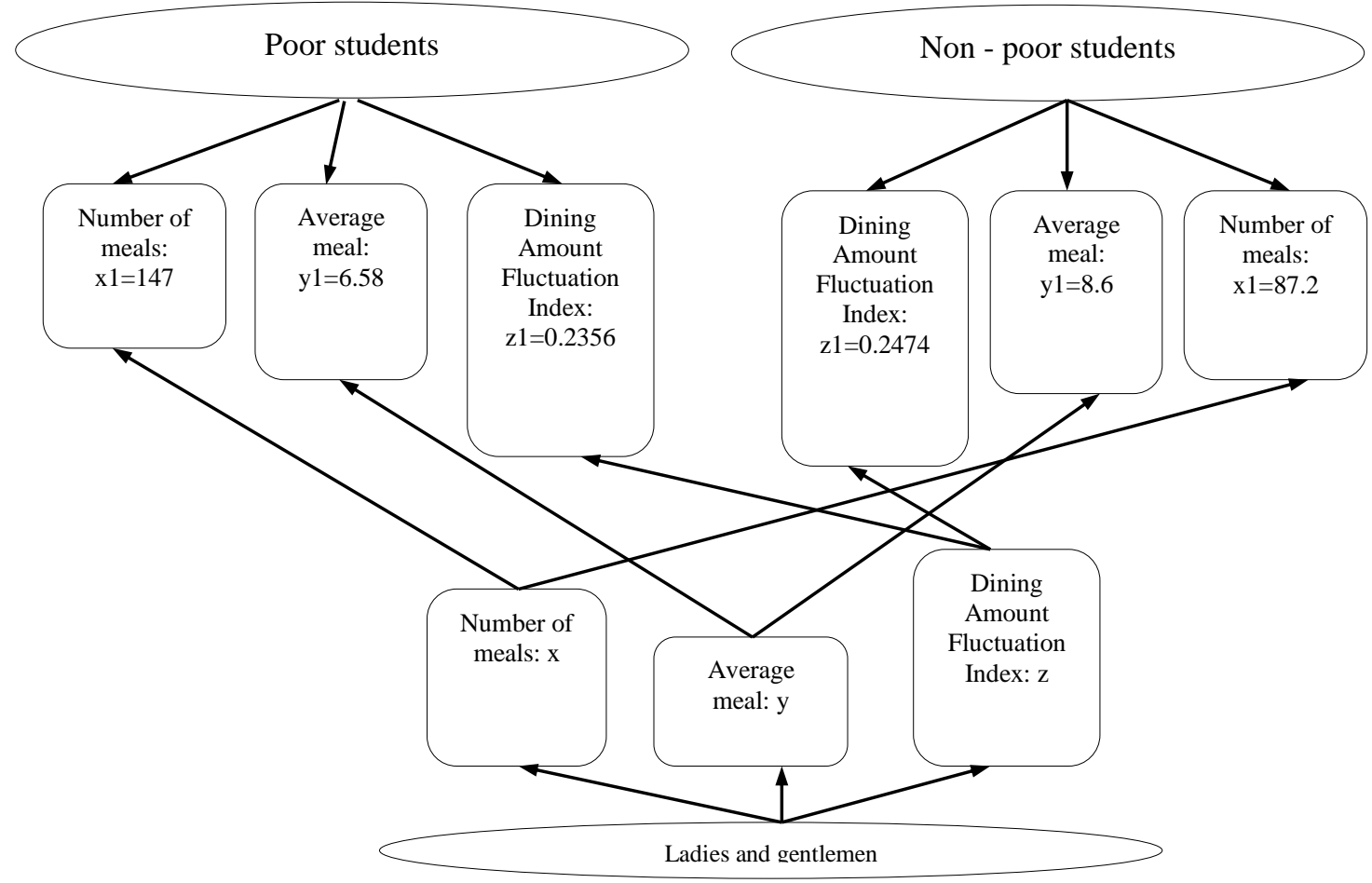

Fig. 1. Poverty index after normalized treatment 
Poverty index formula: $\mathrm{P}=1-(\mathrm{Li}-\mathrm{maxL}) /(\operatorname{maxL}-\mathrm{minL})$

Poverty index reflects the deviation degree of students and poverty standard line, which can reflect students ' poverty more intuitively. In the poverty index $\mathrm{p}$; for students with poverty standard line distance minl, MaxL respectively for the nearest distance with the poverty standard line with the furthest distance ranges between 0 to 1 . The higher the index, the greater the probability of the student's poverty; Conversely, the lower the index, the lower the concept of poverty.

\section{SUMMARY}

It is an effective supplement to the current subsidy system to adopt large data technology in the financial support work of college poor students in order to reduce students ' real life status in the most objective and comprehensive way. Through the analysis of the large data of students ' consumption, it can also be used to evaluate the poor students ' subsidy system in colleges and universities, and to excavate the low consumption level of the student group so as to adopt the subsidy measures to realize the "precision poverty alleviation" funded by the impoverished students.

\section{ACKNOWLEDGEMENT}

(1) 2017 "13th five-year plan" education scientific planning key project of gansu province "advanced education targeted poverty alleviation research"(Item no.: GS [2017] GHBZ034);

(2) Northwest national university 2017 central university project fund. (Item no.:31920170079);

(3) Research and practice on the course process reform of digital electronic technology in northwest nationalities university in 2017. (Item no.:2017XJJG-22);

(4) In 2017, the special fund for basic scientific research operation of the central university of northwest nationalities university. (Item no.:31920170141);
(5) In 2016, the youth team of the central university project fund of northwest nationalities university. (Item no.:31920160003);

(6) Supported by Program for Changjiang Scholars and Innovative Research Team in University (IRT_16R36).

\section{REFERENCES}

[1] Hexia Bi. A review on the identification and research of impoverished college students at home and abroad [J]. Comparative education Studies, 2009,31 (01)(In Chinese)

[2] Shen. A sociological review of poverty research in China [A]. The essence of Chinese poverty alleviation papers [c].:,2001:24.(In Chinese)

[3] Pang Lijuan, Hu Fu, Han Xiaoyu. Paying attention to the poor students in colleges and universities: Problems, causes and countermeasures [J]. Education review at Peking University, 2004 (2): 39-42.(In Chinese)

[4] Ding Guilan, Zhou Yanhua. The realistic predicament and countermeasures of the identification of the impoverished college students [J]. Education and Occupation, 2010 (26): 33-35.(In Chinese)

[5] Jundongxing, Cong, Fangfang, Wu Haiyan, Liu Qinu. On the construction of University's intelligent campus under the background of large data [J]. Journal of East (Natural Science Edition), 2015 (S1)(In Chinese)

[6] Jin Qingqing, Chan Weining, Zhou Minchi, Zhou Ao-ying. Benchmark for data management systems: from traditional databases to emerging large data [J]. Journal of Computer Science, 2015,38 (01): 18-34(In Chinese)

[7] Shu Wenying. Investigation and analysis on the present situation of impoverished students in Gansu Province [J]. Science and technology Higher Education Research, 2009,28 (02): 77-80(In Chinese)

[8] Dong Yang, Miao Jingsen. Thinking of poverty alleviation in large data age [J]. Cooperative economy and Technology, 2016, (14): 189-190(In Chinese)

[9] Wu Chaowen, Jin, Sun Yannan. A study on the precision subsidy model of impoverished college students in large Data environment $[J]$ Heilongjiang higher education Research, 2016, (12): 41-44.(In Chinese) 